\title{
Book Review: Handbook of Research on New Literacies
}

\author{
Eylem Simsek \\ Turkish Air Forces, Turkey
}

This book is edited by Julie Coiro, Michele Knobel, Colin Lankshear, and Donald J. Leu. It was published in 2009 by Routledge of the Taylor and Francis Group, London/New York. The book has $1351+x v i i$ pages; the ISBN is 9780805856521.

This edited handbook has six main parts with a total of 38 chapters. The first main part is about Methodologies, the second Knowledge and Inquiry, the third Communication, the fourth Popular Culture, Community, and Citizenship in the Context of Everyday Literacies, the fifth Instructional Practices and Assessment, and the final chapter Multiple Perspectives on New Literacies Research. The book also provides descriptive information about the authors writing the chapters. There are two carefully-prepared indexes at the end, one for the authors and the second for the subjects.

It appears that the authors, most of whom are internationally recognized scholars in the field of new literacies, have been selected on the basis of their leadership and innovative research in their particular areas of investigation. Considering their academic backgrounds and professional accomplishments, it is clear that each author has an established reputation in his/her respective research area. The authors taking part in the book usually come from the areas of social semiotics and multimodality, online research methodology, ethnographies of new literacies, multimedia learning, cognition and instruction, social blogging, gaming research, information science, instant messaging, computer-mediated communications, elearning and learning management systems, cultural influences on educational technologies, online navigation, reading comprehension, child and adolescent literacy, qualitative research methods, experimental research, and many other relevant areas of inquiry that are taking place in and around new literacies today.

The editors indicate that during a period when the Internet has deeply altered our literacy lives, the Handbook of Research on New Literacies provides a central resource to support the emergence of new literacies research. It brings together leading scholars from around the world to review research in their area, from the perspectives they find to provide the greatest insight. The editors also expect that the Handbook provides central leadership for this newly emerging field, directing scholars to the fundamental issues, theoretical perspectives, and/or interdisciplinary research on new literacies.

As literacy and technology converge on the Internet, many scholars from different fields are moving their research into this area. They find that the constructs emerging in new literacies research inform their own work in productive ways. At the same time, it is increasingly clear that new literacies research also affects societies, education systems, and public policies in a variety of powerful ways. As a consequence, educators, policy makers, employers, and the public at large all recognize that these new literacies of the Internet and related technologies such as social media will be central to the most important literacy and learning issues of the 
new generations in today's digital world. After reading the entire book, one easily reaches to the conclusion that it is time to apprehend the emergence of this relatively new area of interdisciplinary research, to inform others about crucial elements of new literacies, and to begin the construction of an important new era of scientific inquiry. The book reflects, on behalf of both the editors and the authors, a serious effort to accomplish all of these essential goals or functions.

Who is the audience? The editors give a clear answer to this question: From the scope of the book, it is understood that this Handbook is prepared mainly for established scholars and promising researchers working in related areas of new literacies. More specifically, the book is prepared for members of international literacy research community including scholars from traditional reading and writing areas as well as scholars from information science, media studies, educational technology, cognitive science, educational psychology, communications, library science, linguistics, computer-mediated communication, computer science, social studies education, and other related areas that find new online literacies to be an important area of investigation. Graduate students in these disciplines will also find the collection of research reviews to be useful, particularly the final section providing reprints of milestone studies in the area along with commentaries by leading scholars. Finally, given recent interest in data-driven public policies around the world, a secondary audience of the book may be policy makers and school administrators who seek executive summaries of the latest research to inform their own decisions regarding digital citizenship and new literacies.

Regarding the general structure and contents of the book, the reader can easily comprehend and follow the flow of information. After an initial chapter by the editors introducing the book, the next five sections represent the primary areas in which important developments have occurred particularly during the last several decades or are still happening as a byproduct of the technological revolution and the information explosion.

Part I is about "Methodologies". It addresses major issues introduced by the broad range of methodologies with research on new literacies is currently taking place. The sweep of these chapters demonstrates the extensive range of current work, from ethnographic approaches to experimental studies.

There are seven chapters in the first section. They cover topics like connective ethnography of online/offline literacy networks; large scale quantitative research on new technology in teaching and learning; converging traditions of research on media and information literacies; the conduct of qualitative interviews; researching multimodal texts; experimental and quasiexperimental approaches to the study of new literacies.

Part II is on "Knowledge and Inquiry." The contributors in this section introduce a wide range of different perspectives fundamental to understanding how best to use the informational potential of the Internet and other digital contexts to acquire knowledge.

This section has seven chapters. The topics in the chapters deal with learning, change, and power as competing frames of technology and literacy; the Web as a source of information for students in K-12 education; understanding research on navigation in complex digital environments; the changing landscape of text and comprehension in the age of new literacies; exploring culture in the design of new technologies of literacy; multimedia literacy; multiliteracies and metalanguage. 
Part III deals with "Communications." The authors in this section review the latest research occurring in new communication contexts such as blogs, instant messaging, and other social networking tools. The articles in this section also explore the roles that gender and language play during new online literacy practices.

The third section covers four chapters on topics such as mediating technologies and second language learning; Weblog literacy; cross-disciplinary research into instant messaging; gender in online communication.

Part IV is titled "Popular Culture, Community, and Citizenship: Everyday Literacies." This section addresses research in new literacy spaces such as the online and offline worlds of gaming, anime, manga, and fan fiction, as well as the range of challenges associated issues of popular culture, identity, citizenship, online collaborative community projects and other aspects of everyday literacies. New ways of thinking about classroom instruction and assessment are introduced.

There are seven chapters in this section. They deal with topics like intersections of popular culture, identities, and new literacies research; college students and new literacy practices; the new literacy spaces of anime, manga, and fanfiction; cognition and literacy in massively multiplayer online games; video-game literacy; community, culture, and citizenship in cyberspace; new literacies and community inquiry.

Part V is about "Instructional Practices and Assessment." This section covers new literacies research in classrooms ranging from elementary school to higher education. It addresses ways in which we might consider assessing the new literacies beginning to appear in a variety of educational contexts.

This section includes eight chapters regarding topics such as digital writing in the early years; teaching popular culture texts in the classroom; using new media in the secondary English classroom; critical literacy, education, and today's Internet; multimodal instructional practices; assessing new literacies in science and mathematics; learning management systems and virtual learning environments.

Part VI as the last section of the book deals with "Multiple Perspectives on New Literacies Research." It includes five reprinted articles that have been identified by the editors and section contributors as central to the fields in which they work, one from each main section. It also includes commentaries on each study by two leaders in the area of new literacy research, each of whom brings a different perspective to the task. This approach provides the readers with taking advantage of the benefits that diverse, alternative or opposing perspectives present as collectively building this relatively new area of investigation.

The printed articles that appeared and commented on in this section include (a) "Savannah: Mobile Gaming and Learning" by Facer et al.; (b) "The Nature of Middle School Learners' Science Content Understandings with the Use of Online Resources" by Hoffman et al.; (c) "Instant Messaging, Literacies and Social Identities" by Lewis and Fabos; (d) "Literacy and the Design of the Self: A Case Study of a Teenager Writing on the Internet" by Lam; (e) "The Journey Ahead: Thirteen Teachers Report How the Internet Influences Literacy and Literacy Instruction in Their K-12 Classrooms" by Karchmer. As mentioned earlier, two commentaries are presented about each of these five reprinted articles in this special section. 
The book has several distinctive characteristics. First of all, a diverse editorial team with a wide range of research interests prepared the book. Their backgrounds include school literacies, professional development, public policy, and different technologies. Secondly, international contributors wrote the chapters. Of them 34 authors from North America, 10 from Australia, 7 from the United Kingdom, 2 from the Netherlands, and 1 each from Norway and South Africa. Third, an extensive, rich, and diverse collection of research reviews are included. The book contains 43 reviews of research, including 10 commentaries to five collectively and carefully selected reprinted articles. Fourth, multiple theoretical conceptualizations are presented. The editors did not pick up a preferred or privileged perspective; instead, they provided alternative views to better comprehend the issues. Finally, there exists a commentary section on selected milestone articles. This unique feature gives the readers a sense of diverse perspectives that can be brought to bear on even the most rigorous research.

Overall, the Handbook of Research on New Literacies provides conceptual, theoretical, and methodological frameworks for an emerging field without unduly foreclosing on potentially valuable perspectives and epistemological approaches. The approach in the book is to allow leading researchers to collectively define central constructs, major issues, alternative research methods, and practical implications through their individual work, not to impose a single perspective upon a young or newly emerging field. Such an interdisciplinary approach takes full advantage of various perspectives about what new literacies are and how they might be studied by considering all the relevant components.

Correspondence: Eylem Simsek, Ph.D., Major, First Combined Air Operations Center, Turkish Air Forces, Eskisehir, Turkey 